\title{
Multiplication végétative et conservation in vitro chez le poireau (Allium porrum L.)
}

Claire DORE

avec la collaboration technique de Florence CharLot et Jean-Charles LeSCURE

I.N.R.A., Station de génétique et d'amélioration des plantes, route de Saint-Cyr, F 78026 Versailles Cedex

Les méthodes de multiplication et de conservation décrites ici sont également applicables à l'ail et à l'échalote.

Mots clés additionnels : Allium, culture in vitro, production de semences, ail, échalote.

In vitro cloning and storage in leek (Allium porrum L.)

Vegetative multiplication is very useful for seed production of several Allium crops. In vitro cloning is a promising solution but the number of plantlets obtained from the mother plant remains too small. A method with successive multiplication cycles has been tried out for leek. It involves stimulating latent meristems located at the basal part of the plantlet. In vitro storage allows transfer into soil to be delayed until a favorable season. The multiplication and storage methods described here can be successfully applied to garlic and shallot.

Additional key words :Allium, vegetative multiplication, tissue culture, conservation, seed production, garlic, shallot.

\section{INTRODUCTION}

Le genre Allium qui appartient à la famille des Liliacées comporte plusieurs espèces cultivées d'importance économique, en particulier l'oignon (A. cepa L.), le poireau ( $A$. porrum $\mathrm{L}$.), l'ail ( $A$. sativum $\mathrm{L}$.) et l'échalote $(A$. ascalonicum L.) dont plusieurs sont multipliés végétativement par bulbe.

Les possibilités de multiplication conforme in vitro ont été étudiées par plusieurs auteurs, soit à partir de bulbes (Hussey, 1978; Falavigna \& Hussey, 1980 ; BHOJWANI, 1980 ; NAGY, 1984), soit à partir d'inflorescences (DUNSTAN \& SHORT, 1979; DORÉ \& SCHWEISGUTH, 1980).

On obtient, selon l'équilibre des substances de croissance employé, des plantules ou des bulbilles.

Dans le cas où le bulbe est le matériel de départ, les plantules (ou les bulbilles) obtenues proviennent du développement de méristèmes axillaires ou sont d'origine adventive (HuSSEY, 1978). Dans le cas où l'inflorescence est utilisée comme matériel de départ, les plantules (ou les bulbilles) néoformées résultent de la réversion vers l'état végétatif des plus jeunes fleurs à la faveur d'une modification de l'équilibre hormonal créée par la suppression des fleurs les plus âgées. Il existe un antagonisme entre le développement des boutons floraux et l'initiation de plantules (DORÉ \& SCHWEISGUTH, 1980) (fig. 1).

Dans tous les cas, le nombre de plantules obtenu est limité (de l'ordre d'une centaine) ce qui ne permet pas de répondre aux objectifs de production de semences.

Chez le poireau, l'intérêt de structures variétales hybrides (variété hybride de clones ou variété synthétique de clones) a été démontré (SCHWEISGUTH, 1983). Dans ce contexte, la multiplication végétative est indis- 


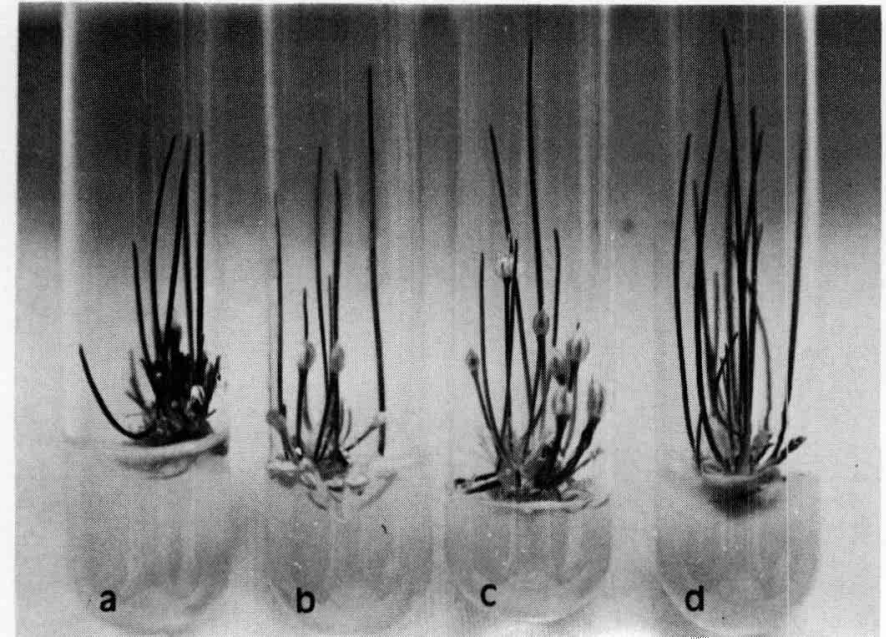

Figure 1

Antagonisme entre le développement des boutons floraux et l'initiation de petites plantes

- a et $d=$ la plupart des boutons floraux ont été supprimés,

- bet $c=$ quelques boutons floraux ont été supprimés.

Antagonism between flower bud development and plantlet initiation

- $a$ and $d=$ most of the flower buds have been cut off.

- $b$ and $c=$ a few flower buds have been cut off

pensable pour réaliser le clonage des parents directis de l'hybride, ou les composants dans le cas de la variété synthétique. L'effectif requis est alors de plusieurs milliers de plants pour chacun des génotypes.

Nous décrivons ici une méthode de multiplication par cycles successifs et un mode de conservation que nous avons mis au point chez le poireau.

\section{MATÉRIEL ET MÉTHODES}

\section{A. Matériel végétal}

De jeunes inflorescences de nombreux génotypes mâles-stériles et mâles-fertiles de poireau ont été fournies par B. SCHWEISGUTH, sélectionneur du poireau à la Station de Génétique et d'Amélioration des Plantes à l'I.N.R.A. de Versailles.

\section{B. Culture in vitro}

Le protocole suivi pour l'obtention des premières plantules et les conditions de culture ont déjà été décrits (DORÉ \& SCHWEISGUTH, 1980).

Quand les plantules obtenues sont bien développées, un repiquage est effectué sur le milieu $P_{2}$ contenant la solution minérale de MURASHIGE \& SKOOG (1962), les vitamines de GAMBORG et al. (1968) et $1 \mathrm{mg} / 1$ d'acide (indole-3)- 4 butyrique et de benzyladénine, après avoir supprimé les racines et coupé en deux longitudinalement chaque plantule.

Les différentes plantules obtenues sont ensuite incividualisées sur le milieu de base sans substance de croissance $\left(\mathrm{P}_{0}\right)$. Ce milieu favorise l'enracinement des pantules (fig. 2).

Une alternance de repiquages sur les milieux $P_{2}$ et $P_{0}$ est pratiquée jusqu'à obtention du nombre de plantules désirées.

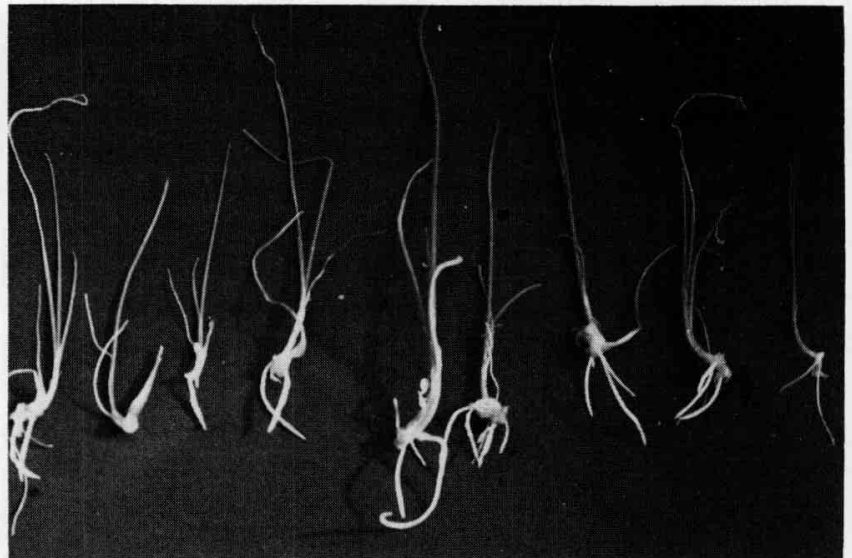

Figure 2

Plantules racinées prêtes à être repiquées en terre.

Rooted plantlets ready for transfer into soil.

\section{Conservation in vitro}

Les plantules racinées et individualisées peuvent être conservées :

- soit sur le milieu $P_{0}$ en tubes ou en bocaux scellés par un film en matière plastique pendant 6 mois sans aucune intervention dans une chambre de culture (température continue de $7{ }^{\circ} \mathrm{C}$, photopériode de 10 heures, éclairement de 1000 lux);

- soit en les plaçant à racines nues en «botte », dans un bocal vide stérilisé et scellé avec un film en matière plastique, dans les mêmes conditions d'environnement que ci-dessus.

\section{Repiquage en terre}

Les plantules sont repiquées dans un mélange terreau, tourbe, sable $(1: 1: 1)$ dans des «mini-serres » $\left(^{*}\right)$ et placées dans une chambre climatisée (thermopériode $15-20{ }^{\circ} \mathrm{C}$, photopériode de durée variable selon les objectifs, éclairement de 10000 lux, humidité relative de $60 \%$ ). Les couvercles des mini-serres sont ouverts progressivement pour permettre l'endurcissement des plantes.

Trois semaines après repiquage en terre, celles-ci peuvent être transférées en serre ou en châssis (fig. 3).

\section{RÉSULTATS ET DISCUSSION}

Le taux de multiplication obtenu est de 3 à 7 suivant les génotypes après chaque repiquage sur $\mathrm{P}_{2}$. La durée d'un cycle de multiplication est de l'ordre de six semaines.

Les plantules produites sur le milieu $\mathrm{P}_{2}$ résultent de l'activité des méristèmes latents situés à la base du plateau du bulbe sans passage par un cal. Cette activité est stimulée par la présence de cytokinine et par le découpage en deux du plateau qui supprime la domi-

*Etablissements Boulllard Frères S.A., F 71370 Saint-GermainDu-Plain. 


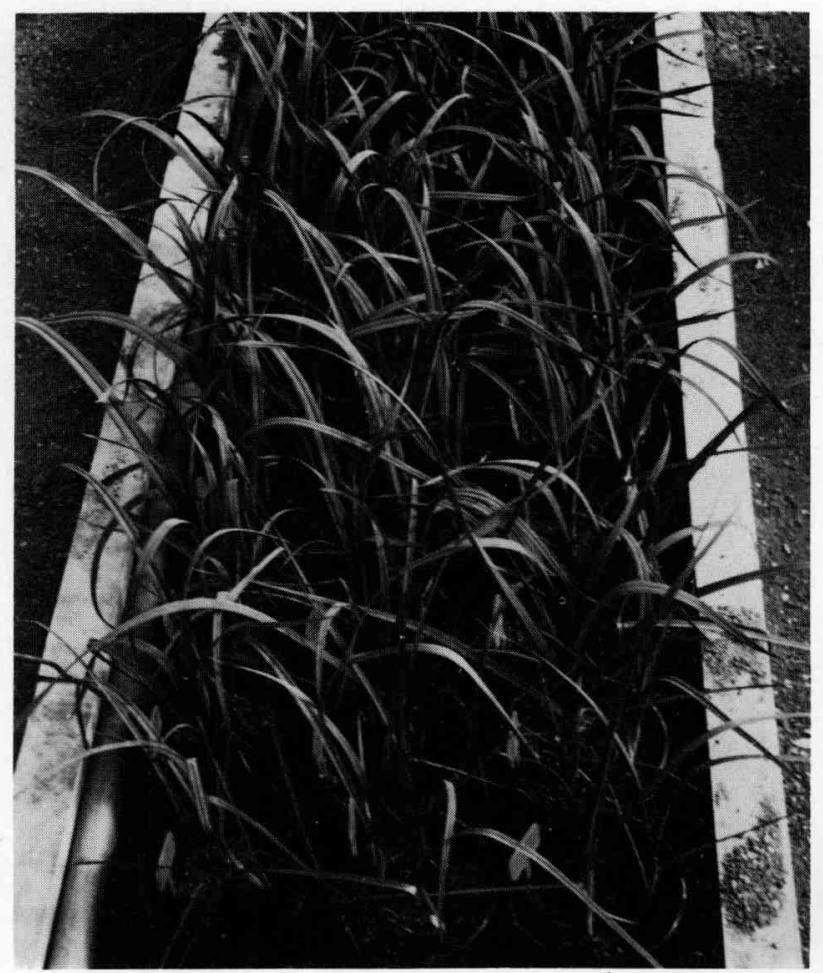

Figure 3

Un clone de poireau en serre, provenant de multiplication in vitro. A micropropagated clone of leek in the greenhouse.

nance apicale, si importante chez de nombreuses Monocotylédones, du méristème central (HuSSEY, 1976).

Les résultats obtenus chez le poireau sont transposables à l'ail et à l'échalote. Le calibre des plantules obtenues est un point essentiel dont dépend la réussite de la méthode : il détermine le nombre de méristèmes végétatifs latents qui constitueront les futures plantules. Ce facteur est d'ailleurs également important en conditions naturelles pour des espèces comme l'ail (J. P. LeROUX, communication personnelle); ou bien l'échalote où "plus le bulbe est lourd (donc plus les feuilles sont nombreuses), plus il possède de points végétatifs qui donneront naissance à de nouveaux bulbes" (COHAT, 1982). C'est ce même principe qui s'applique pour la multiplication in vitro.

La possibilité de conserver le matériel végétal au stade plantule in vitro permet de le stocker en attendant la saison favorable à la croissance de la plante en conditions naturelles. Ceci est particulièrement utile chez des espèces, comme les Allium, sensibles à la longueur du jour.

\section{CONCLUSION}

La méthode de multiplication végétative efficace rapportée ici associée à celle de la conservation des plantules permet de disposer d'un système utilisable dans la pratique par des sélectionneurs ou des multiplicateurs de semences. Son efficacité permet d'envisager son intégration dans le schéma de production des semences de certains Allium comme le poireau et l'ail :

- chez le poireau, dans le cadre de la création de variétés synthétiques de clones, la multiplication in vitro des composants garantirait la stabilité de la variété,

- chez l'ail et l'échalote, la possibilité de réaliser les premières générations de multiplication, après élimination des virus par culture de méristèmes à l'abri des éventuelles recontaminations virales, représente une intéressante perspective.

Reçu le 18 décembre 1987. Accepté le 19 avril 1988.

\section{REMERCIEMENTS}

L'auteur remercie B. SchweIsGuth de la Station de Génétique et d'Amélioration des Plantes de l'I.N.R.A. de Versailles pour la fourniture de matériel végétal et sa précieuse collaboration dans la réalisation de ce travail.

\section{RÉFÉRENCES BIBLIOGRAPHIQUES}

Bhojwani S. S., 1980. In vitro propagation of garlic by shoot proliferation. Sci. Hortic., 13, 1, 47-52.

Cohat J., 1982. Influence du calibre des bulbes de semences d'échalote sur leur taux de multiplication et leur rendement. Pépiniéristes, Hortic. Maraîchers, 21-24.

Doré C., Schweisguth B., 1980. Multiplication végétative du poireau pour la production de semences. C. R. Réunion Eucarpia, Application de la culture in vitro à l'amélioration des plantes potagères, Versailles, 54-57.

Dunstan D. I., Short K. C., 1979. Shoot production from the flower head of Allium cepa L. Sci. Hortic., 10, 345-356.

Falavigna A., Hussey G., 1980. Moltiplicazione in vitro della cipolla (Allium cepa L.). Genet. Agr., 34, 165-166.
Gamborg O. L., Miller R., Ojima K., 1968. Nutrient requirements of suspension culture of soybean root cells. Exp. Cell. Res., 50, 151-158.

Hussey G., 1976. In vitro release of axillary shoots from apical dominance in monocotyledonous plantlets. Ann. Bot., 40, 1323-25.

Hussey G., 1978. In vitro propagation of the onion Allium cepa L. by axillary and adventitious shoot proliferation. Sci. Hortic., 9, 227-236.

Murashige T., Skoog F., 1962. A revised medium for rapid growth and bioassays with tobacco tissue culture. Physiol. Plant., 15, 473-497.

Nagy J. I., 1984. Mericloning of onion (Allium cepa L.). In : Plant Tissue and Cell Culture, Application to Crop Improvement. Inter. Symp., Olomouc, Tchécoslovaquie, p. 129.

Schweisguth B., 1983. Which varietal structure for leek? Allium conference, Mendel-Frimmel Geselschaft, Freising, 19-21 juillet 1983. 